\title{
THE MYELOABLATIVE DRUG BUSULFAN CONVERTS CYSTEINE TO DEHYDROALANINE AND LANTHIONINE IN REDOXINS
}

Michele Scian, ${ }^{1}$ Miklos Guttman, ${ }^{1}$ Samantha D. Bouldin, ${ }^{2}$ Caryn E. Outten, ${ }^{2}$ and William M. Atkins ${ }^{1 *}$

${ }^{1}$ Department of Medicinal Chemistry, Box 357610, University of Washington, Seattle, WA 98195-7610

${ }^{2}$ Department of Chemistry and Biochemistry, University of South Carolina, Columbia, SC 29208 
Table S1. Theoretical and experimental $\mathrm{m} / \mathrm{z}$ values for the $\mathrm{hGrx}-1$ tryptic peptide ${ }^{15} \mathrm{VVVFIKPTCPYCR}^{27}$ chemically modified by reaction with busulfan, TCEP and GSH.

\begin{tabular}{|c|c|c|c|c|c|c|c|c|}
\hline \multirow[t]{3}{*}{ Grx-1 peptide } & \multicolumn{2}{|c|}{$[\mathbf{M}+\mathbf{H}]^{+}$} & \multicolumn{2}{|c|}{$[\mathrm{M}+2 \mathrm{H}]^{2+}$} & \multicolumn{2}{|c|}{$[\mathbf{M}+\mathbf{3 H}]^{3+}$} & \multicolumn{2}{|c|}{$[\mathrm{M}+4 \mathrm{H}]^{4+}$} \\
\hline & \multicolumn{8}{|c|}{ Monoisotopic mass (Da) } \\
\hline & Theoretical & Found & Theoretical & Found & Theoretical & Found & Theoretical & Found \\
\hline VVVFIKP & 1547.8403 & 11547.8385 & 774.4238 & 774.4247 & 516.6183 & 516.6166 & 387.7155 & \\
\hline & $1635.8750^{*}$ & & $818.4411^{*}$ & 818.4370 & $545.9632 *$ & 545.9669 & $409.7242 *$ & 409.7231 \\
\hline VVVFIKPT- & 1490.8188 & 1490.8160 & 745.9130 & 745.9142 & 497.6111 & 497.6169 & 373.4602 & \\
\hline & 1578.8535 & 1578.8484 & 789.9304 & 789.9342 & 526.9560 & 526.9630 & 395.4688 & 395.4668 \\
\hline & 1854.9241 & & 927.9657 & 927.9561 & 618.9795 & 618.9806 & 464.4865 & 464.4816 \\
\hline & $1797.9009^{*}$ & & $899.4541 *$ & 899.4471 & $599.9718^{*}$ & 599.9743 & $450.2307 *$ & 450.2293 \\
\hline & $1885.9356^{*}$ & & 943.4714 & 943.4695 & 629.3167 & 629.3173 & 472.2393 & 472.2458 \\
\hline
\end{tabular}

$*[\mathrm{M}]^{+},[\mathrm{M}+\mathrm{H}]^{+2},[\mathrm{M}+2 \mathrm{H}]^{+3},[\mathrm{M}+3 \mathrm{H}]^{+4}$.

Table S2. Theoretical and experimental $\mathrm{m} / \mathrm{z}$ values for the $\mathrm{hThrx}-1$ tryptic peptide ${ }^{22}$ LVVVDFSATWCGPCK ${ }^{36}$ chemically modified by reaction with busulfan.

\begin{tabular}{|c|c|c|c|c|c|c|c|c|}
\hline \multirow[t]{3}{*}{ Thrx-1 peptide } & \multicolumn{2}{|c|}{$[\mathbf{M}+\mathbf{H}]^{+}$} & \multicolumn{2}{|c|}{$[\mathrm{M}+2 \mathrm{H}]^{2+}$} & \multicolumn{2}{|c|}{$[\mathrm{M}+\mathbf{3 H}]^{3+}$} & \multicolumn{2}{|c|}{$[\mathrm{M}+4 \mathrm{H}]^{4+}$} \\
\hline & \multicolumn{8}{|c|}{ Monoisotopic mass (Da) } \\
\hline & Theoretical & Found & Theoretical & Found & Theoretical & Found & Theoretical & Found \\
\hline & 1647.8199 & & 824.4136 & 824.4110 & 549.9448 & & 412.7104 & \\
\hline & $1735.8546^{*}$ & & $868.4309 *$ & 869.4326 & $579.2897 *$ & 579.2933 & $434.7191 *$ & \\
\hline VVDFSATW $-\mathrm{C}-$ & 1590.7985 & 1590.7874 & 795.9029 & 795.9005 & 530.9377 & 530.9407 & 398.4551 & \\
\hline $\begin{array}{cc}s & s \\
l & 1 \\
\mathrm{CH}_{2} & \mathrm{CH}_{2} \\
1 & 1 \\
\text { LVVVDFSATW } & \mathrm{C}-\mathrm{G}-\mathrm{P}-\mathrm{C}-\mathrm{K}\end{array}$ & 1678.8331 & & 839.9202 & 839.9229 & 560.2826 & 560.2799 & 420.4637 & \\
\hline
\end{tabular}

* $[\mathrm{M}]^{+},[\mathrm{M}+\mathrm{H}]^{+2},[\mathrm{M}+2 \mathrm{H}]^{+3},[\mathrm{M}+3 \mathrm{H}]^{+4}$. 

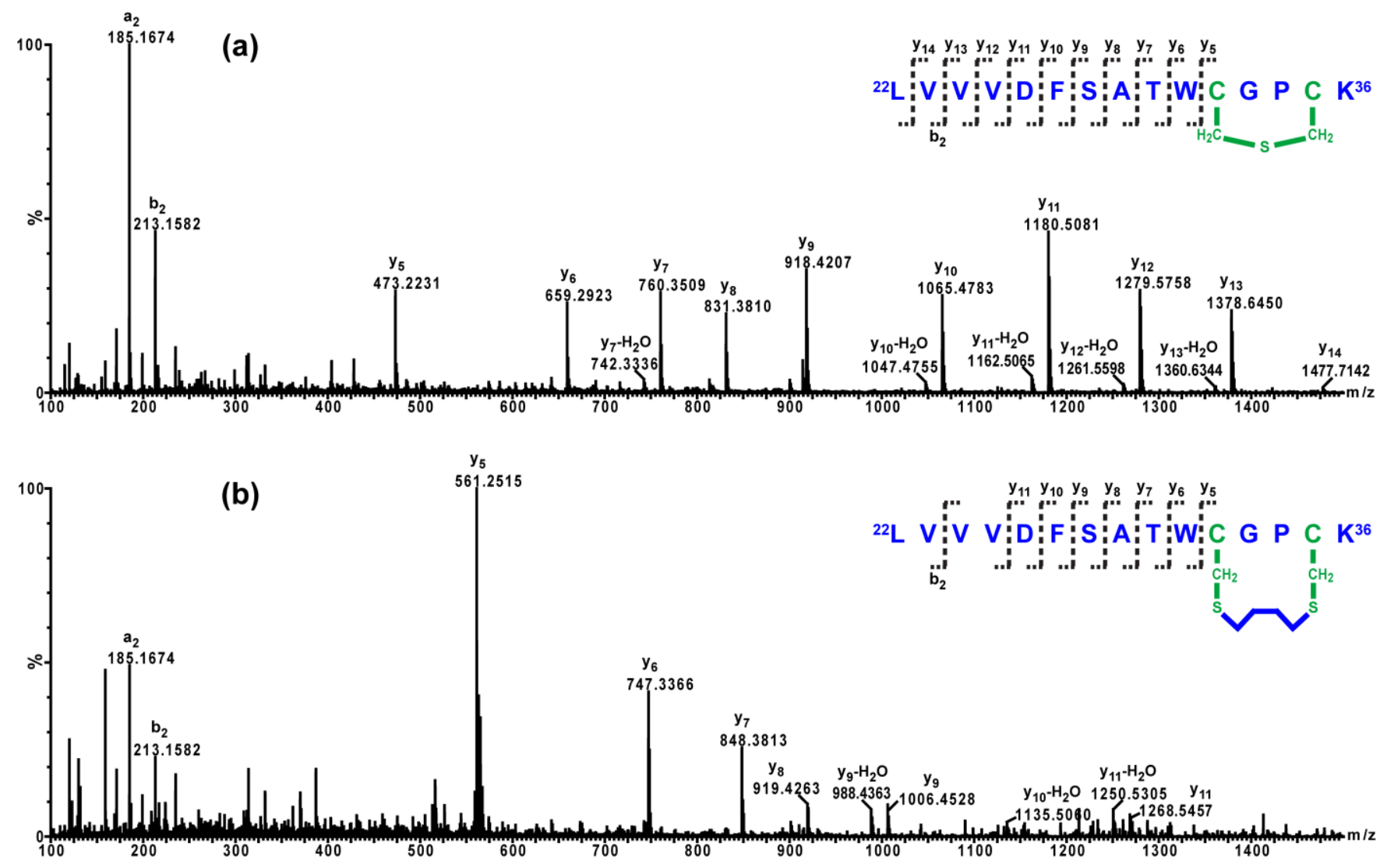

Figure S1. MS/MS spectra of the Thrx-1 tryptic peptides Cyclo-peptide (a) and CL-peptide (b) obtained from fragmentation of precursor ions with mass $795.90 \mathrm{Da}\left(\right.$ i.e. $[\mathrm{M}+2 \mathrm{H}]^{+2}$ ) and $560.28 \mathrm{Da}$ (i.e. $[\mathrm{M}+3 \mathrm{H}]^{+3}$ ), respectively. 

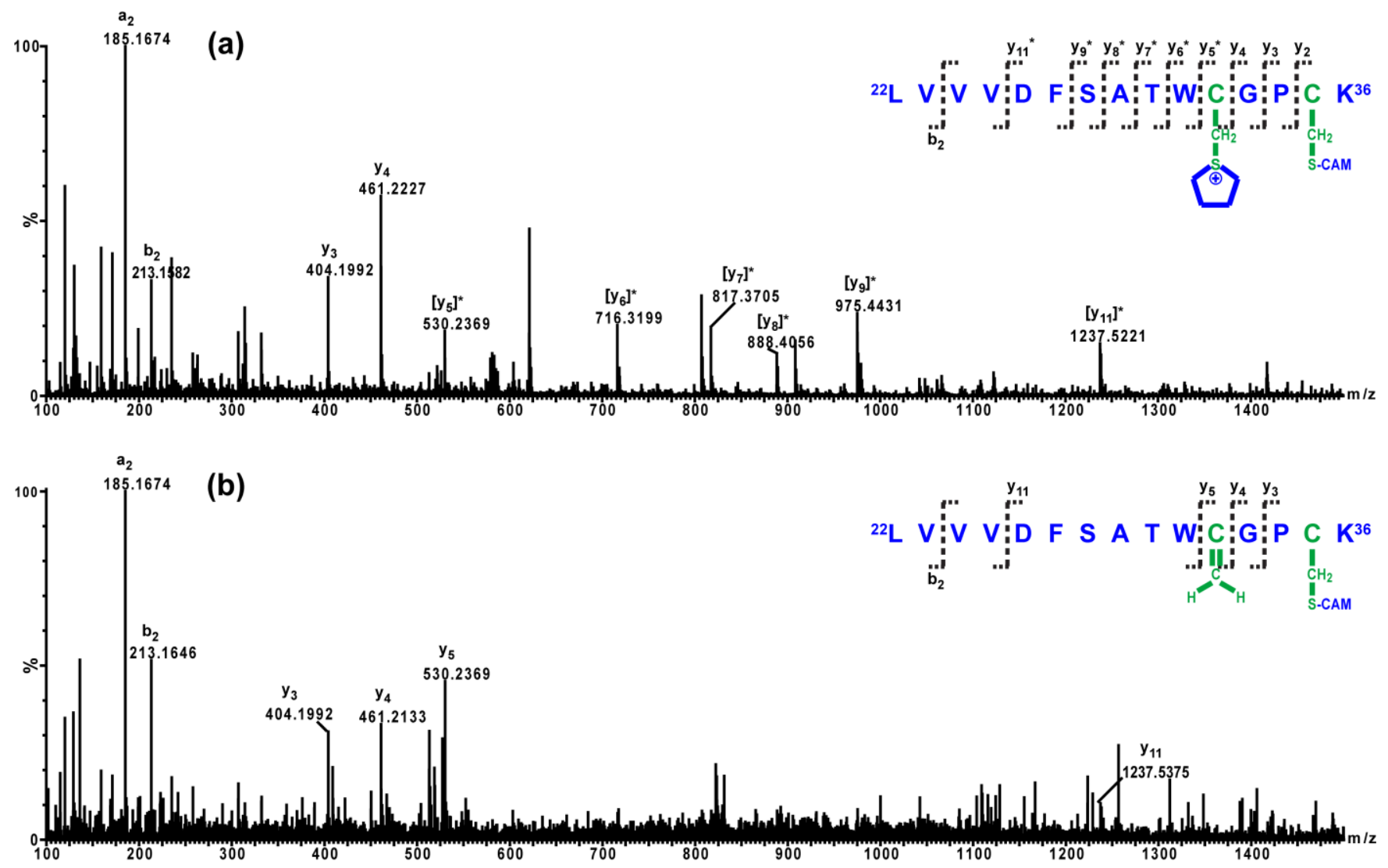

Figure S2. MS/MS spectra of the Thrx-1 tryptic peptides $\mathrm{THT}^{+}$-peptide (a) and DHA-peptide (b) obtained from fragmentation of precursor ions with mass $579.29 \mathrm{Da}$ (i.e. $[\mathrm{M}+2 \mathrm{H}]^{+3}$ ) and $824.41 \mathrm{Da}\left(\right.$ i.e. $[\mathrm{M}+2 \mathrm{H}]^{+2}$ ), respectively. Atoms shown in green belong to sidechain of cysteine residues whereas those depicted in blue are from busulfan. The asterisk indicates fragments characteristic of the DHA-peptide formed by gas-phase decomposition of the $\mathrm{THT}^{+}$-peptide. 


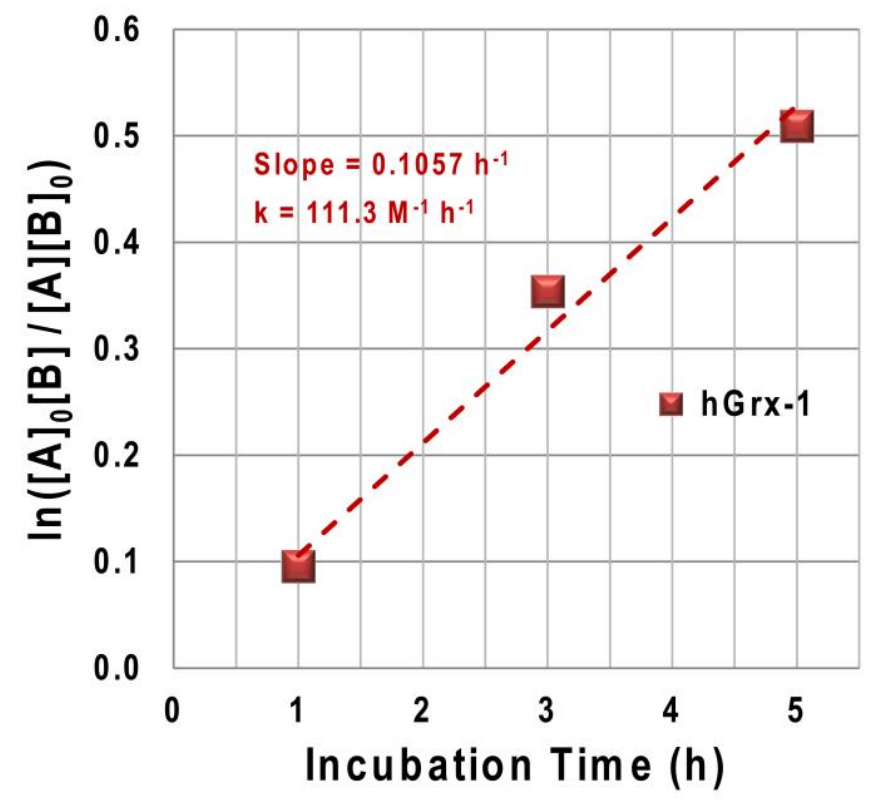

Figure S3. Determination of the reaction rate constant, $k$, for the bimolecular reaction of hGrx-1 $\left([\mathrm{A}]_{0}=50 \mu \mathrm{M}\right)$ with busulfan $\left([\mathrm{B}]_{0}=1\right.$ $\mathrm{mM})$. In a $2^{\text {nd }}$ order reaction, the linear plot of $\ln \left([\mathrm{A}]_{0}[\mathrm{~B}] /[\mathrm{A}][\mathrm{B}]_{0}\right)$ vs. time has slope $=\mathrm{k}\left([\mathrm{B}]_{0}-[\mathrm{A}]_{0}\right)$. 